laparotomy but who was too ill to undergo resection at that time.

R. W. Marcuson and J. A. Farman ${ }^{13}$ have now been able to review 122 collected cases of ischaemic disease of the colon. Of these, 98 were over the age of 50, and of the 24 younger patients three were diabetic and six were women taking oral contraceptives. There were 103 cases of ischaemic colitis and 16 examples of gangrene of the colon. All sites in the large bowel were involved, including the rectum, but 71 of the cases involved the transverse colon, splenic flexure, or descending colon. Unless there is evidence of spreading peritonitis, in which case surgery must be undertaken, the authors advise that all cases should be treated conservatively. Nearly half will resolve and require no further treatment. The remainder will develop stricture, but even some of these may dilate as they mature, and surgery is indicated only for obstruction or when malignant disease cannot be excluded.

\footnotetext{
1 Jackson, B. B., Occlusion of Superior Mesenteric Artery. Springfield,

2 Berger, R. L., and Byrne, J. J., Surgery, Gynaecology, and Obstetrics, 1961, 112, 529

3 Ellis, H., in Abdominal Operations, ed. R. Maingot, 5th edn., 2, 1497. New York, Appleton-Century-Crofts, 1969.

4 Droller, H., Age and Ageing, 1972, 1, 162.

5 Elliott, J. W., Annals of Surgery, 1895, 21, 9.

- Klass, A. A., Fournal of the International College of Surgeons, 1953, 20, 687. Marston, A., Annals of the Royal College of Surgeons of England, 1972, 50, 29.

${ }^{8}$ Venables, C. W., Ellis, H., and Smith, A. D. M., Lancet, 1966, 2, 1390.

Dick, A. P., Graff, R., Gregg, D. Mc. G., Peters, N., and Sarner, M., Gut, 1967, 8, 206.

10 Marston, A., Pheils, M. T., Thomas, M. L., and Morson, B. C., Gut, 1966, 7, 1.

11 Marston, A., Marcuson, R. W., Chapman, M., and Arthur, J. F., Gut, $1969,10,121$.

13 Rowe-Jones, C. D., British Medical fournal, 1969, $1,361$.

13 Marcuson, R. W., and Farman, J. A., Proceedings of the Royal Society of Medicine, 1971, 64, 1080 .
}

\section{Tragic Dilemma}

A recent case in the Hull juvenile court was concerned with principles that have been the subject of much anxious debate among doctors for some time. No transcript of evidence was taken, but from press reports ${ }^{1} 2$ the circumstances of the case appear to be as follows. A baby boy of 13 months suffered from spina bifida and hydrocephalus. In the opinion of medical consultants the baby needed surgical treatment to save his life. The parents refused their consent to operation, and the director of social services, acting under the Hull Social Services Committee, therefore applied to the court for the child to be taken into the care of the local authority. The court made the required order, and after sitting in private the social services committee gave its consent to the operation.

There can be no suggestion that anyone here had any but the most scrupulous regard for the child's welfare. The law was observed in the spirit and the letter, and it is clear that all parties in the case acted from the highest motives. But in this tragic dilemma of what was best for the baby the parents and committee found themselves in irreconcilable opposition.

In a press interview with the parents ${ }^{3}$ the mother was reported to have said:

"We love our son like any other parents, but we don't want him to lie in hospital suffering operation after operation and be used as a guinea-pig. There is no religion involved in this. We would be overjoyed if a miracle happened and he became well again. The terrible truth is that he will never walk, no matter how many operations he has. If he falls over while sitting up in bed, he remains in that position until a nurse pushes him back again. It was heartbreaking enough to learn that he was handicapped, without doctors prolonging our agony. This dreadful dilemma could befall any family at any time and they might find themselves getting the rubber stamp treatment. If courts and doctors are going to decide about life, it won't be long before they are sitting in judgment about death."

The view of the social services committee was given in the following statement ${ }^{1}$ :

"We had regard on the one hand to the fact that the parents had refused to give their consent to the operation and, on the other, the opinion of the medical consultants that it is essential that the child should have this operation. The local authority has a clear duty to have regard to the welfare of the child in its widest sense and we are satisfied that in view of what the medical consultants have said about this case that it will be in the child's best interests for him to undergo this operation."

Local authorities are rarely called upon to seek statutory powers to remove a child from its parents' control so that it may have medical treatment to which the parents object. The use of these powers is certainly something the medical profession should scrutinize closely, for it is ultimately on a medical man's authority that the law intervenes to sever the closest of all human bonds, between parent and child. Medical decisions with such painful implications are rarely likely to be simple to reach, and one feature of any case that must provoke the most careful thought is the expected results of treatment. When a child is sick and can be restored to normal health by treatment, the advice a doctor should give is much clearer than when the proposed treatment will not restore the child to normal health. These are matters that can be judged only in relation to each individual case. The problem of what treatment-if any, in some circumsstances-should be given to babies with gross congenital defects ${ }^{4}$ can be difficult enough for a doctor to offer parents frank advice on when he is confident that they are likely to accept it. When he knows they do not agree with him the burden of decision is all the heavier.

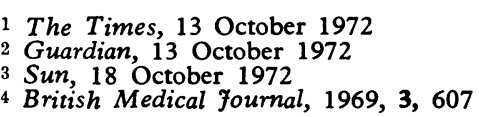

\section{Corticosteroids in Pulmonary Aspergillosis}

Clear examples of immunopathological mechanisms in allergic disease of the lungs are provided by the different clinical disorders caused by Aspergillus fumigatus, which can grow in the lungs. ${ }^{1}$ Analysis of the allergic factors shows the place of corticosteroids in treatment.

In atopic patients the spores act as allergens, stimulating the production of reaginic (IgE) antibody, which mediates immediate type I asthmatic reactions. Disodium cromoglycate inhibits these reactions, ${ }^{2}$ whereas corticosteroids do not, ${ }^{3}$ nor do they modify appreciably the immediate skin test reaction. The production in these patients of precipitins capable of mediating type III immune-complex reactions is attributed to the growth of the spores in the bronchi. A. fumigatus is cultured more frequently from the sputum of asthmatic than of non-asthmatic people. ${ }^{4}$ The presence together of the types I and III allergy is closely associated with the com- 
plication of the asthma by "pulmonary eosinophilia."3 4 Variable, transitory, recurrent peribronchial infiltrations or collapse-consolidation shadows appear, suggesting diagnoses such as pneumonia or tuberculosis. ${ }^{5}$ Sputum plugs containing fungal hyphae may be expectorated. The pulmonary shadows, with their commonly associated and characteristic proximal bronchiectasis and the upper-lobe fibrosis of chronic cases, are attributed to the tissue-damaging effects of type III reactions to antigens produced locally by the growing fungus.

Type I reactions may facilitate the production of the type III reactions. ${ }^{16}$ In atopic persons IgE-mediated reactions, with their associated eosinophilia, can fulfil this role. Because of the importance of the type I reaction in this context the demonstration of type I allergy by prick tests in patients with asthma and pulmonary eosinophilia is a valuable diagnostic test for allergic bronchopulmonary aspergillosis. ${ }^{3}$

The dual nature of the allergic reactions is shown by the succession of immediate and late skin and bronchial reactions, the latter accompanied in some cases by fever and leucocytosis. Corticosteroids are potent inhibitors of the late type III reactions, with little or no effect on the immediate type I reactions. They also hasten the resolution, where this is still possible, of the pulmonary shadows, at the same time reducing the volume of sputum and its content of $A$. fumigatus. ${ }^{3}$

Aspergillus fumigatus is also well-known for its saprophytic growth in areas of damaged lung to produce the characteristic "fungus ball." This presents on $x$-ray as a rounded shadow with a halo of air and in some cases with a thickened surrounding wall. This shadow is persistent, disappearing only occasionally if the fungal mass is expectorated or dies. Aspergillomata may appear in the openhealed cavities of pulmonary tuberculosis. ${ }^{7}$ While allergy does not play a part in their development, about $30 \%$ of patients have been found to give immediate prick test reactions, and there are now suggestions that in some cases type III reactions aggravate the disease process $^{89}$ and that corticosteroids may be of value in the treatment of this. ${ }^{9}$ An IgG antibody in non-atopic persons capable of mediating type I skin test reactions has been described recently in man. ${ }^{10}$ This may provide the introductory mechanism for the type III reaction, though it seems not to be associated with an eosinophil response and it seems unlikely, or less likely than IgE antibody, to be able to produce immediate asthmatic reactions. This IgG antibody has a lesser affinity for most cells than IgE antibody.

The fungal mass of the aspergilloma provides abundant antigenic stimulation, shown by the commonly strong precipitin test reaction. ${ }^{11}$ Since allergy is not a feature of aspergilloma, it is the precipitin rather than the skin test which is of high diagnostic value. Aspergilloma is uncommon in allergic bronchopulmonary aspergillosis, being found in 8 out of 111 cases in one survey. ${ }^{3}$ In view of the frequency of bronchiectasis in the latter it is surprising that they are not more frequent. Perhaps the immunological reactivity of the atopic person may militate against saprophytic growth of the fungus.

The problem of corticosteroids and fungal invasiveness has to be considered. They are commonly prescribed for patients with allergic bronchopulmonary aspergillosis, and their beneficial effects together with lack of evidence that they stimulate invasion by the lesion, suggest that they are safe in this respect. Similarly in aspergilloma, where even local invasion is limited if present at all, corticosteroids can safely be tried, if indicated. It is in patients with reticuloendothelial disease, or on immunosuppressive drugs, or with immunodeficiency that invasion by fungi is apt to occur and corticosteroids may favour it.

The problems of treatment in pulmonary aspergillosis are complicated by many factors. For instance, potent antifungal agents against $A$. fumigatus are lacking, and in aspergilloma such agents might not be able to penetrate to the lesion. In allergic bronchopulmonary aspergillosis it is the allergic state which is important, and repeated inhalation of spores is certain. Corticosteroids are the mainstay of treatment in this disease, ${ }^{3}$ though it is not yet clear whether they should be given continuously, to try to prevent episodes of pulmonary infiltration; or during such episodes, by which time they may be too late to prevent some of the damage; or mainly when the asthma cannot be effectively controlled by other measures. It now seems that they may also have a place in the treatment of those patients with aspergilloma in whom allergic reactions are occurring. ${ }^{9}$

\footnotetext{
1 Pepys, J., Monographs in Allergy. Basle, Karger, 1969, 4, 39.

Pepys, J., Hargreave, F. E., Chan, M., and McCarthy, D. S., Lancet, $1968,2,134$

3 McCarthy, D. S., and Pepys, J., Clinical Allergy, 1971, 1, 261.

4 Pepys, J., Riddell, R. W., Citron, K. M., Clayton, Y. M., and Short, E. I., American Review of Respiratory Diseases, 1959, 80, 167.

McCarthy, D. S., Simon, G., and Hargreave, F. E., Clinical Radiology,

1970, 21, 366 .
- Henson, P. M., and Cochrane, C. G., in Cellular and Humoral Mechanisms in Anaphylaxis and Allergy, ed. H. Z. Movat, p. 129. Basle, Karger, 1969. British Thoracic and Tuberculosis Association, Tubercle, 1970, 51, 227.

8 Stevens, E. A. M., Hilvering, C., and Orie, N. G. M., Thorax, 1970, 25, 11. 9 Davies, D., and Somner, A. R., Thorax, 1972, 27, 156 .

10 Parish, W. E., Lancet, 1970, 2, 591

11 Longbottom, J. L., and Pepys, J., fournal of Pathology and Bacteriology, $1964,88,141$.
}

\section{Joint Meeting at Vancouver}

Next June's joint meeting of the British and Canadian Medical Associations at Vancouver (Supplement, p. 83) promises some first-class reviews of several growing points in medicine as well as a lively social programme. The mornings will be devoted to a single plenary session on subjects such as immunobiology and medical genetics, while the afternoon will offer a choice of two meetings on equally important but perhaps more everyday matters such as hyperthyroidism, peripheral vascular disease, and peptic ulcer. The unusual choice of subject at the concluding session-"The Business of Medicine"-should provoke interesting discussion by both Canadians and Britons, who among them are likely to have worked in a wide variety of medical care systems.

Apart from several principal speakers from Vancouver itself, and trips to local hospitals, the important contribution of British Columbia to preventive medicine has been recognized in a session on the early diagnosis of cervical cancer. The full social programme offers items of local interest, and after the meeting doctors will be able to sample the beauties of Canada or the U.S.A. in a wide variety of tours. This conference offers them an easy opportunity of brushing up their medicine and meeting colleagues in a beautiful environment, and then refreshing themselves with an early summer holiday before returning to this country.

We record with great regret the death on 2 December of Lord Rosenheim, emeritus professor of medicine in the University of London. 